\title{
Urinary nitrite in symptomatic and asymptomatic urinary infection
}

\author{
H R POWELL, D A MCCREDIE, AND M A RITCHIE
}

Renal Unit and Department of Microbiology, Royal Children's Hospital, Victoria, Australia

SUMMARY The dipstrip test for urinary nitrite is fairly unreliable in symptomatic urinary infections and only $104(52 \%)$ of 200 symptomatic children with urinary infection attending an emergency department had a positive result. The test yielded positive results, however, in 83 of 100 outpatients with largely asymptomatic urinary infection attending a follow up clinic because of known predisposition to urinary infection. This difference was highly significant.

The finding of urinary nitrite is highly specific for urinary infection and only $1 \%$ of 300 uninfected urine specimens gave a positive result.

After addition of a broth culture of Escherichia coli to sterile urine incubation at $37^{\circ} \mathrm{C}$ for four to six hours was required before the nitrite test yielded positive results. This suggests that frequency of micturition in urinary infection reduces the reliability of the nitrite test. On the other hand, the use of overnight, first morning urine specimens may further improve the sensitivity. If nitrite testing is used for screening for urinary infection at home, however, patients should be warned not to rely on a negative result in the presence of symptoms of urinary infection.

The reliability of the nitrite test for urinary tract infection (UTI) has been investigated by several workers, most of whom have concluded that false positive results were rare and that the test had a high specificity for UTI. The sensitivity of the test, defined as the proportion of infections with positive nitrite reactions, has been reported to be low $(21-59 \%)$ by some authors ${ }^{1-7}$ and high $(80-93 \%)$ by others. $^{8-12}$ Those reporting low sensitivity advise against the use of the test in screening patients at risk of UTI, while it is advocated by those who have found high sensitivity.

The nitrite test is based on the ability of most infecting bacteria to reduce dietary derived urinary nitrate to nitrite. The observation that bacteria that reduce nitrate require incubation in urine for some hours before a test for nitrite yields a positive result was consistent with the finding that a higher yield of positive results is obtained from samples collected early in the morning, from patients with infected urine, than from samples collected at random during the day. ${ }^{12}$ These observations suggested that frequency of micturition in patients with UTI could be a possible cause of false negative nitrite reactions. False negative results, however, were-uncommon during outpatient follow up of well patients prone to UTI. If the nitrite test had a high sensitivity in such asymptomatic patients it could be useful in screening patients at risk of UTI. Screening at home could then enable early detection and treatment before symptoms arise.

This paper examines the sensitivity of urine nitrite tests in patients attending an emergency department with symptomatic UTI compared with a group of patients with UTI but without symptoms. An explanation is offered for the observed difference based on the nitrite generation time in bladder urine.

\section{Patients and methods}

Two hundred patients, aged 3 weeks to 16 years (mean 5.9 years), whose urine cultures grew $\geqslant 10^{5}$ bacteria/ml in pure growth of a single organism from midstream or suprapubically aspirated specimens, attended the emergency department of our hospital between January and September 1985. All these patients had symptoms that led to attendance at the emergency department and to urine culture. As complaints of frequency, dysuria, and other symptoms are dependent on individual, subjective factors, however, we have not attempted to analyse the symptoms that led to the urine test. Patients who had only plastic bag specimens were excluded. Suprapubically aspirated specimens were obtained from 17 of these children who were less than 3 years 
of age (mean 7.8 months) and in all the number of organisms was $\geqslant 10^{5} / \mathrm{ml}$.

Between October 1984 and September 1985, 100 outpatients aged 3 to 14 years (mean 9.0 years) attended a follow up clinic and were found to have $\geqslant 10^{5} \mathrm{bacteria} / \mathrm{ml}$ in midstream urine specimens. These patients were being followed because of known predisposition to UTI and their urine tests were performed during regular follow up visits when most patients were asymptomatic.

Ninety three of these 100 patients with UTI who attended the follow up clinic were investigated by micturating cystography and either intravenous urography or ultrasonography. Fifty three $(57 \%)$ had lesions causing urinary stasis (44 vesicoureteric reflux, three bladder diverticula, four neuropathic bladder, and two partial pelviureteric obstruction). The other 40 had no radiological abnormalities.

The results of nitrite tests were also ascertained in midstream urine samples with low or zero bacterial counts $\left(<10^{4}\right.$ bacteria/ml) from 200 patients attending the emergency department and 100 patients attending the follow up clinic to determine the frequency of false positive results in uninfected urine.

Urine specimens were collected on arrival in the emergency or outpatient departments and tested immediately. No attempt was made to obtain first morning specimens. Urine nitrite tests were carried out using Boehringer Mannheim Nitur-test dipstrips and were read by laboratory medical scientists. Nitrate was not added to the specimens.

To determine the time required to generate nitrite in urine at body temperature a broth culture of Escherichia coli was added to 20 sterile urine samples negative for nitrite to produce a final organism concentration of $10^{5} / \mathrm{ml}$. Samples were then incubated at $37^{\circ} \mathrm{C}$ and tested every 30 minutes for nitrite reaction. When a positive nitrite reaction occurred the sample was cultured on dipslides (labslides, Bunzl Medical and Laboratory Products).

\section{Results}

Of the 200 symptomatic patients attending the emergency department with $\geqslant 10^{5}$ bacteria/ml in midstream or suprapubically aspirated urine specimens, $104(52 \%)$ had a nitrite test that yielded a positive result. Only seven of the 17 suprapubically aspirated specimens from infants gave a positive result. Of the 100 outpatients with $\geqslant 10^{5}$ bacteria $/ \mathrm{ml}$ identified in midstream urine specimens obtained on routine clinic visits, $83(83 \%)$ had a nitrite test that yielded a positive result. The difference in the proportion of infections positive for nitrite between the symptomatic patients attending the emergency department and the largely asymptomatic patients attending routine outpatient follow up was highly significant $\left(\chi^{2}=25 \cdot 98, \mathrm{p}<0 \cdot 0001\right)$.

The distribution of nitrite reactions according to the infecting organism is shown in the Table. The absence of any nitrite positive reactions in streptococcal UTI reflects the known absence of the nitrate reductase enzyme in these organisms. ${ }^{58}$

When $10^{5} \mathrm{E}$. coli/ml were added to 20 sterile urine specimens and incubated at $37^{\circ} \mathrm{C}$ one specimen became nitrite positive by four hours, 10 specimens by four and a half hours, 16 by five hours, and 19 by six hours. One sample still had no detectable nitrite at six hours. All 20 urine samples supported growth of the organisms as shown by culture at the end of the incubation.

To assess whether anatomical conditions with urinary stasis led to increased sensitivity of the nitrite test, the sensitivity of the test in infected patients with radiological abnormalities was compared with the sensitivity in those with normal urinary tracts. Of the 53 patients with radiological abnormalities attending follow up clinic, five had streptococcal UTI. As streptococci do not reduce nitrate these five patients were excluded from the analysis. Of the remaining 48 patients, four $(8 \%)$ had tests that produced false negative results. Of the 40 patients with radiologically normal urinary tracts, attending follow up clinic, one had a streptococcal UTI and was excluded, and five $(13 \%)$ of the remainder had tests that gave false negative results. Clearly, the difference was not significant $\left(\chi^{2}=0 \cdot 11\right)$.

Of 200 urine specimens with $<10^{4}$ bacteria/ml from patients attending the emergency department, two had tests that yielded positive results, and of the 100 patients with low bacterial counts attending follow up clinic, only one had a positive result. Of these three patients whose tests apparently yielded false positive results, one had recently begun treatment with antibiotics.

Table Nitrite test results according to infecting bacteria

\begin{tabular}{|c|c|c|c|c|}
\hline \multirow[t]{2}{*}{ Bacteria } & \multicolumn{2}{|c|}{$\begin{array}{l}\text { Emergency department } \\
\text { patients }\end{array}$} & \multicolumn{2}{|c|}{$\begin{array}{l}\text { Follow up clinic } \\
\text { patients }\end{array}$} \\
\hline & Total & $\begin{array}{l}\text { Nitrite } \\
\text { positive }\end{array}$ & Total & $\begin{array}{l}\text { Nitrite } \\
\text { positive }\end{array}$ \\
\hline Escherichia coli & 165 & 93 & 87 & 77 \\
\hline Streptococcus spp & 5 & 0 & 6 & 0 \\
\hline Staphylococcus spp & 12 & 3 & 2 & 2 \\
\hline Klebsiella spp & 5 & 2 & 2 & 1 \\
\hline Proteus spp & 9 & 6 & 1 & 1 \\
\hline Pseudomonas spp & 4 & 0 & 1 & 1 \\
\hline Citrobacter spp & 0 & 0 & 1 & 1 \\
\hline Total & 200 & 104 & 100 & 83 \\
\hline
\end{tabular}




\section{Discussion}

The findings of this study show a considerable difference in the sensitivity of the urine nitrite test as an indicator of UTI in patients with symptomatic and asymptomatic infections. This difference could explain the wide variation in sensitivity reported in the published reports. Because of the high frequency of negative results of nitrite assay in patients with symptomatic UTI, the value of the test is limited to those in whom a positive result is obtained. More reliability can be placed on the sensitivity of the test in the follow up management of asymptomatic patients, although $17 \%$ of such infections were not detected.

Kass has shown that urine cultures with $\geqslant 10^{5}$ bacteria/ $\mathrm{ml}$ are reproducible evidence of infection in $80 \%$ of asymptomatic women. ${ }^{13}$ Although the criteria of UTI in children are not so well defined, cultures of a single organism in numbers of $\geqslant 10^{5} / \mathrm{ml}$ in midstream urine samples are generally regarded as sufficient evidence for diagnosis of UTI. As in adults, however, a small proportion of such cultures probably do not result from UTI but from gross contamination, and these specimens could account for some of the apparently false negative results seen in our patients.

Urine aspirated from the bladder by suprapubic puncture should normally be sterile and any number of organisms generally indicates infection. In all our cases with positive cultures from suprapubically aspirated specimens colony counts of $\geqslant 105 / \mathrm{ml}$ were obtained. These specimens were all from symptomatic infants and their lower frequency of positive nitrite reactions may be related to a shorter incubation time in the bladder.

This study confirms that incubation at $37^{\circ} \mathrm{C}$ of at least four to six hours is required for generation of detectable nitrite in infected urine samples, and therefore patients with a high frequency of micturition might be expected to have a high likelihood of false negative results. It is suggested that the higher sensitivity of the nitrite test in the patients attending follow up clinic was due to the infections being mostly asymptomatic and not associated with frequency of micturition.

By increasing the time that infected urine is retained in the urinary tract, lesions such as vesicoureteric reflux and bladder diverticula would be expected to be associated with fewer false negative results of nitrite tests. While there was no significant difference in the sensitivity of the nitrite test in asymptomatic patients with and without these lesions, a greater proportion of the patients attending follow up clinic had radiological abnormalities than would be expected in the unselected patients attend- ing the emergency department. This factor may also have enhanced the sensitivity of the test in the patients attending follow up clinic.

The higher sensitivity of nitrite tests in asymptomatic infections suggests that the tests could be useful in the monitoring of patients prone to UTI with structural abnormalities of the urinary tract. Weekly, or twice weekly, urine tests at home have been advocated ${ }^{8}$ By ensuring that only overnight, first morning urine specimens are nitrite tested by asymptomatic patients undertaking home surveillance a degree of sensitivity higher than that observed in our patients attending follow up clinic might be expected. ${ }^{12}$

Although we have found a false negative rate of $17 \%$ in asymptomatic patients attending follow up clinic, the findings suggest that home screening would detect at least $83 \%$ of asymptomatic UTI, allowing treatment before symptoms develop. The low incidence of false positive results would not lead to unnecessary investigation of large numbers of uninfected patients. Patients undertaking home screening should be warned, however, that nitrite tests are much less reliable in the presence of symptoms of urinary tract infection.

\section{References}

I Skelton IJ, Hogan M, Stokes B, Hurst JA. Urinary tract infections in childhood. The place of the nitrite test. Med J Aust 1977;1:882-6.

2 Gillenwater JY, Cleason CH, Lohr JA. Home urine cultures by the dipstrip method: results in 289 cultures. Pediatrics 1976; 58:508-12.

3 Barbin GK, Thorley JD, Reinarz JA. Simplified microscopy for rapid detection of significant bacteriuria in random urine specimens. J Clin Microbiol 1978;7:286-9.

4 James GP, Paul KL, Fuller KB. Urinary nitrite and urinary tract infection. Am J Clin Pathol 1978;70:671-8.

5 Lie JT. Evaluation of a nitrite test kit (Stat-test) for the detection of significant bacteriuria. J Clin Pathol 1968;21:443-4.

6 Miriovsky MF. Office analysis of bacteriuria. Am Fam Physician 1979;19:121-6.

${ }^{7}$ Kincaid-Smith $\mathrm{P}$, Bullen $\mathrm{M}$, Fussell U, Mills J, Huston $\mathrm{N}$, Goon $\mathrm{F}$. The reliability of screening tests for bacteriuria in pregnancy. Lancet 1964;ii:61-2.

${ }^{*}$ Scheifele DW, Smith AL. Home-testing for recurrent bacteriuria using nitrite strips. Am J Dis Child 1978;132:46-8.

${ }^{9}$ Randolf MF, Morris K. Instant screening for bacteriuria in children: analysis of a dipstick. $J$ Pediatr 1974;84:246-8.

${ }^{10}$ Kunin CM, DeGroote JE. Self-screening for significant bacteriuria: evaluation of dipstrip combination nitrite/culture test. JAMA 1975;231:1349-53.

"Kunin CM, DeGroote JE, Uehling D, Ramgotal V. Detection of urinary tract infection in 3-5 year old girls by mothers using nitrite indicator strips. Pediatrics 1976;57:829-37.

12 Czerwinski A, Wilkerson RG, Merrill JA, Bruden B, Colmore JP. Further evaluation of the Griess test to detect significant bacteriuria. Am J Obstet Gynecol 1971;110:677-81.

13 Kass EH. Asymptomatic infections of the urinary tract. Trans Assoc Am Physicians 1956;69:56-64.

Correspondence to Dr H R Powell, Royal Children's Hospital, Flemington Road, Parkville, Victoria 3052, Australia.

Received 22 August 1986 